\title{
The Mechanical, the Historical, and the Statistical
}

\section{Practical Purposes of This Meeting}

This meeting is the outcome of conversations which resulted from the recent book of Dr. Henderson on "The Fitness of the Environment." Yet this company is not called for the sake of discussing, on the present occasion, that book, or any of the scientific problems which it more directly considers. The connection, then, between Dr. Henderson's book and this evening's undertaking needs some explanation. As you know from the wording of the call to which you have so kindly responded, one principal purpose which I have in mind as I address you is practical. I shall ask you, before the evening is done, to give some thought to the question: Is it advisable for us to meet again occasionally, as opportunity offers, in order to discuss some questions of common scientific interest? You represent various departments of research. Is it worth while for you, or some of you, at your own pleasure, to come together in such a way as the present one, in order to take counsel about different problems which belong, not only to a single science, and not only to some special group of sciences, but also to the realm

[Reprinted from Science, n.s. (1914) 39:55 I-66.] 
which is common to a decidedly wide and varied range of scientific inquiries?

My part in this evening's discussion is determined by this practical question. I can not come here as a representative of any one department of research in natural science. I am limited in my present undertaking to such an appeal as a student of philosophy may have a right to address to a company of scientific men, when he wishes to ask them a practical question whose answer concerns them all.

The only justification which I have for addressing you is that the habits of a student of philosophy, and, in particular, of a student of logic, makes him sensitive to the value of a comparative scrutiny of the methods, the conceptions and the problems of various sciences.

If the main topic of the evening is a question relating to the practical value of some new mode of cooperation, in which a number of representatives of different departments of scientific research are to be asked to take part, the student of philosophy may possibly serve as a sort of travelling agent. For the kind of cooperation to which I have been asked to invite your attention would involve, if it succeeded, certain journeys which some of you might thereby be induced to make into the provinces of your colleagues. Widely traveled though all of you are, these journeys may lead occasionally to novel incidents, and may please or arouse you in new ways. My business, I say, is to act this evening merely as such a tourist agent, describing and praising as I can the new kind and combination of journeys to which my agency proposes to invite you.

Philosophy itself, in so far as it is a legitimate calling at all, may in fact be compared to a sort of Cook's bureau. Its servants are taught to speak various languages-all of them ill-and to know little of the inner life of the numerous foreign lands to which they guide the feet, or check the luggage of their fellow-men.

But if new comparative studies of the ideas of various and widely sundered provinces of research are to be carried out at all, Cook's agents, tedious as they often are, have their part to play. Regard me, then, if you wish to vary the name, as representing this evening some bureau of university travel. 


\section{Preliminary View of the Theoretical Problem of This Paper}

Speaking seriously, let me say that my task, upon its theoretical side, involves undertaking to present to you, in a perspective which may prove to be not wholly familiar, an outline sketch of certain conceptions and methods which actually belong to widely various sciences. These conceptions and methods in some measure concern you all, and, in our day, they are undergoing various changes, and are being applied to new problems.

The problems of each science are its own affair; but they also concern the whole body of scientific workers. To look over a somewhat wide range of scientific work, not for the sake of contributing to the researches of any one special science or group of special sciences, but for the sake of studying for their own sake some of the most general ideas and methods that are used by various scientific workers-this is, at the present time, a legitimate undertaking, and, in view of what has already been done, and is now under way, is not a hopeless undertaking.

The perspective in which such a study may place the problems of other people may help them to understand one another better. My task on its theoretical side is limited this evening to a few such general methodological remarks. These remarks may then lead us back to our practical question.

\section{The Problem of Vitalism}

The name vitalism is often given to those doctrines which have used the hypothesis that the phenomena of living organisms are due to some process which is essentially identical in its nature with the process exemplified by our own conscious voluntary activities. We deliberate, plan and choose. It seems to us as if certain things and occurrences in the world are due to these our plans and choices, and are different from what they would be were our will not a factor in the world-process. On the other hand, some things and events in the natural world-notably the recurrent movements of the heavenly bodies, and the processes which attend the workings of machines, seem to us to be, in some or in many respects essentially different from the processes which result from our 
plans, our choices and our voluntary deeds. What is called a mechanical theory of nature, or, more generally still, materialism, undertakes to account for the vital processes, for the activities of organisms, by supposing that they too are not essentially different from the other material processes, and that they really exemplify the same natural laws which the movements of the heavenly bodies and the workings of machines illustrate.

The contrast between vitalism and materialism is, in the history of science and of philosophy, very ancient. The Greeks began with doctrines which were, in a somewhat confused way, both materialistic and vitalistic. The natural world was viewed as, in one of its aspects, a sort of machine, a chariot whose mechanical movement was an essential feature of its very being. The natural world was also regarded as through and through alive-a world of love and strife, of mixing and of sundering, of wisdom and of something resembling contrivance.

To this early Greek vitalism, which had various forms, the materialism of Democritus opposed a mechanical theory of nature which was much more ingenious and considerate than were the earliest forms in which the machine-like aspect of nature was described. On the whole, however, vitalism, the doctrine that nature acts not in vain, but in an essentially planful and designing way, was predominant in Greek thought.

The greatest Greek vitalist was Aristotle. Materialism remained in the background of ancient thought, and was destined to be revived, and to take on the form of the modern mechanical theory of nature, only after the beginnings of the new science in the seventeenth century of our era.

These ancient problems as to whether nature is rather a mechanism or an expression of something which essentially involves or resembles wisdom and contrivance, are certainly not questions which belong to any one natural science or group of natural sciences. From time to time, however, they come nearer to the surface of popular or of scientific discussion. The present is a moment when a certain interest in various forms of vitalism has once more become prominent in the discussions not only of philosophers and of leaders in popular inquiry, but of some professional students of the natural sciences of life as well.

I do not know how far it will prove to be interesting or profitable for you, as scientific men, to discuss, in your future meetings, 
if you have any future meetings, problems directly connected with vitalism, or with its old opponent, the mechanistic theory of the nature of life. I know only that when we mention such problems we call attention to one of the ancient boundary lines, or, as one may say, to one of the beaches where, in the realms of inquiry, sea and land come face to face with each other; so that two widely constrasting realms of nature here seem to clash. Here, then, the waves of experience tumble, and the tides of opinion rise and fall. Here, then, for that very reason, and especially at this very time, new discoveries are likely to be made in especially impressive ways.

If you are to compare notes, it will therefore not be surprising to find that questions about the relations, the contrasts and the connections of life and of mechanism will become prominent in your discussions. My own preliminary remarks on the classification of scientific methods may well be guided, then, by some interest in the scientific processes which go on upon this old boundary linethis sea-beach-of opinion and of investigation, where the vast and doubtful seas of inquiry into the phenomena of life encounter, as it were, the firm land where the mechanical view of nature finds its best known illustrations.

\section{The Vitalism of Aristotle}

It will help us in our survey of our problems about the contrasting ideas and methods followed by the inorganic sciences on the one hand and the sciences of life on the other hand, if we next say a word about one aspect of Greek vitalism which is frequently neglected.

Life-processes in general resemble our own voluntary human processes, as we have said, in so far as any living organism seems to us as if it were guided by some sort of design, and as if, through a kind of wisdom or contrivance it adjusted means to ends. To say this, however, and even to believe that this seeming is well founded, and that, in some wise living nature really is planful, and does embody something of the nature of will, or of purpose-to assert all this is not yet to decide how close the real resemblance is between the teleology of nature and the choices and contrivances of a man who is planning and who is exerting his will.

As a fact there have been many vitalists who thought nature, 
and in particular organic nature, to be purposive, but who did not believe that nature is clearly aware of her own designs.

There have been many vitalists who conceived of nature as in some sense even divine in its skill, but who did not accept theism either in its primitive or in its more cultivated forms. The design argument in its later theological formulations is not any classic argument for vitalism. All this becomes manifest if you look for a moment at Greek vitalism, and, in particular, at the vitalism of Aristotle.

The Greek vitalists well knew that nature, however wise she seems to be, does not show signs of deliberating like an architect before he builds a house, or of piecing together her works as a carpenter devises a chest or a bed. For the Greek vitalist, and, in particular, for Asistotle, nature fashions, but not as a human mechanic fashions-piecemeal and by trial and error.

Nature's skill is (so such vitalists think) more like that of a creative artist, who does not pause to know how he creates. If ideas inspire the artist, he does not reflect upon what they are. Just so, while the being whom Aristotle calls God, who is conceived to exist quite apart from the world, is indeed self-knowing and is wisely self-observant, Aristotle's God is not the God of the later design argument. For he neither creates nor fashions the natural world. Nature, in Aristotle's opinion, is not God and is not God's handiwork, but is, with a certain instinctive and unconscious wisdom, a sort of artistic imitator of God's wisdom. And this natural process of imitating the divine perfection by quickening a material world with a tendency to be fashioned after a divine pattern-this process constitutes the life of the natural world.

The designs which nature expresses are therefore for Greek vitalism not the conscious designs of anybody-either God or man. They are the creative tendencies which embody themselves in the material world, by a process which we can best compare with the workings of instinct or genius.

Now modern vitalism is far away from its Greek forerunners, but whenever, for any reason, vitalism becomes afresh interesting to any group either of philosophers or of scientific workers, it is well to remember that the contrast and the conflict between a mechanical view of nature and vitalistic view has hardly ever been limited to the decidedly special and artificial antithesis between blind mechanism, on the one hand, and conscious or deliberative 
design, on the other hand. For even our human art is, as Aristotle remarks, partly guided by a skill which is not conscious and is not deliberate. That which, in recent years, Bergson has called élan vital-the creative vital power, was well known, in their own way, to the Greeks.

Different as Bergson's vitalism is from that of Aristotle, the ancient view and Bergson's vitalism have in common the belief that life means a process of which the instinctive skill and the artistic genius of man give examples. The problem of vitalism is always the problem as to how such unconsicous skill, such undeliberative art is made possible.

And so, even in this sketch of the varieties of scientific method, I shall in passing name to you one way in which some of the newest hypotheses may enable us to face, and perhaps in some measure to clarify, the problem as to how this stimulation of conscious designs by processes which are themselves unconsciously or, so to speak, blindly wise, is a possibility in the natural world.

\section{$\mathbf{V}$ Three Types of Knowledge: The Historical, the Mechanical and the Statistical}

So much must suffice as an introductory word regarding those problems about vitalism and mechanism which have recently been revived, and have brought us together. Herewith we are ready to proceed to our classification of the conceptions and the methods which may be used in dealing with such a range of problems as is this.

The attempt to sketch in a preliminary way what these conceptions and methods are can be preserved, I think, from vagueness, if I begin by using the guidance of a man of whom you all are accustomed to think as a true natural philosopher-one who was possessed of a very exact sort of scientific knowledge, and who was a great scientific discoverer. He was also very fond of a comparative study whereby he lighted up his own researches through thoughts that came to him from far-off fields. I refer to Clerk Maxwell. In a paper whereof some fragments are printed in his biography, as well as in various remarks in his published writings, Clerk Maxwell more than once used the classification of scientific knowledge which I shall here employ for our present purpose. Natural science, in so far as it studies the processes of the natural 
world, has three kinds of objects with which it deals. And it adjusts itself to these three kinds of objects by methods which, in each of three fields thus defined, vary widely from one another; while in each of the three fields both the conceptions and the methods used have much in common, and much too whereby each of the three fields differs from the others. The three sorts of objects are: (1) Historical objects, (2) mechanisms, and (3) statistically defined assemblages. The three sorts of methods are: The historical, the mechanical and the statistical.

Clerk Maxwell's few but momentous observations upon these three fields of scientific knowledge have a beautiful brevity, and show a fairly poetical skill of imagination whereby he finds and expresses his illustrations both of scientific ideas and of methods. I can not follow the master in his own skill. And I shall be unable to use his language. I must portray his classification in my own way, and must use my own illustrations.

If you wish to come into closer touch with this aspect of the master's thought, you may use the concluding passage of his famous elementary treatise on the "Theory of Heat," and several remarks in his article on "Atoms" in the ninth edition of the Encyclopedia Britannica. In addition I may refer you to the citations made by Theodore Merz in the eleventh chapter of Volume II of his "History of European Thought in the Nineteenth Century" (pp. 599, 601 and 603).

Let me briefly review, with a few illustrations, this classification of the three fields and the three methods of natural science.

Science deals either with substantial things (such as atoms or organisms) or else with events. Let us confine ourselves here to the works of science in its dealings with natural events and processes. Science deals with the historical when its objects are individual events or complexes of events, such as is a single solar eclipse, or such as is the birth or the death of this man, or the performance of just this act of choice by this individual voluntary agent.

Science deals with the mechanical when its objects are the invariant laws to which all the individual events of some field of inquiry are subject, and when such invariant laws actually exist, and can be used to compute and to predict actual events. Thus, if the acceleration which every individual body belonging to a system of material bodies undergoes depends at every instant, in an in- 
variant way, upon the spatial configuration of the system of bodies at just that moment, the system is a mechanical system-such, for instance, as a system of bodies moving in accordance with the Newtonian law of gravitation.

Science deals, in the third place, with the statistical, when it studies the averages in terms of which aggregates or collections of events can be characterized, and when it considers not the invariant laws, but the always variable possibilities that these averages will be subject to certain uniformities, and will undergo definable changes.

In brief, the object of historical knowledge is the single event, occurring, in the ideally simple case, to an individual thing. A freewill act or an observed eclipse serves as an example. The object of mechanical knowledge is the unchanging natural law under which every event of some type can be subsumed. Sometimes the object of mechanical science may be an individual event, but only in so far as, like the eclipse, it can be predicted by means of such an invariant law. The object of statistical knowledge is not the single event and is not the invariant law but is the relatively uniform behavior of some average constitution, belonging to an aggregate of things and events, and the probability that this average behavior will remain, within limits, approximately, although always imperfectly uniform.

\section{Applications of This Classification}

In view of this classification of the objects of scientific knowledge, you may see at once that the issues between such doctrines as vitalism and a mechanistic account of nature appear, from the point of view of Maxwell's classification, in a somewhat unfamiliar perspective. For one need no longer merely contrast two views, the mechanical and the vitalistic. One now has a third and a mediating point of view to compare with both of them. The result is instructive.

Vitalism, whatever else it involves, always makes prominent some aspect of nature, and in particular some aspect of organic nature, such that this aspect is supposed to be, in some individual case, strictly historical. If an organism is due to a purposive process, if the reactions of an organism are, in any instance, events of the 
nature of conscious or of subconscious deeds-then something unique, historical and novel occurs whenever one of these vital processes is exemplified by an individual event.

On the other hand, if the mechanistic view of nature can exhaustively express the real facts, then the only natural events are of the type which the eclipses exemplify. The single events are, so to speak, points on a curve, selections from an ideal continuum whose constitution is definable in terms of an invariant differential equation.

But the third or statistical mode of viewing nature takes account of another aspect of the processes of nature. The world of the statistical view still contains events supposed to be unique and individual; but from the statistical point of view the main interest lies no longer in each event as it occurs, nor yet in its unique character. The statistical interest is directly concerned with a set or aggregate of events, with a discrete multitude of occurrences. These occurrences may prove to be examples of law. The statistical view is deeply interested in finding that they are examples of law. But the law for which the statistical method seeks is no longer a law that is ideally stable in terms of an invariant differential equation or in terms of any other timeless invariant. When found, the statistical law is an account of a collection of facts in terms of averages involving many events.

This account takes some such form as saying: "The average magnitude or velocity or size or range of the events of the class $C$ is approximately $V$." Or, again, the statistical view succeeds when we can say: "A proportion which is approximately $p$ of the events of the class $a$ have the character $b$." Or finally, one expresses the statistical view when one is able to assert: "There is a probability $q$ that $c$ differs from $d$ by not more than such and such an amount, -say X." All such generalizations, where the objects in question are living organisms, relate to events, but neither to merely historical single events nor to events subject to fixed laws. The statistical laws are probable and approximate laws about numbers of events.

Laws and probabilities, stated in some such form as the one just suggested, constitute the characteristic formulas of the statistical view of nature.

It is easy to illustrate how the statistical view contrasts with both the mechanical and the historical point of view by considering 
how each point of view applies to an event such as is expressed by the assertion: "A killed B."

For a strictly historical point of view this event, this homicide, is an unique occurrence-possibly a free-will act. It falls under moral and criminal laws, but these relate only to its value and its legal consequences. The interest of the case for a judge or a jury lies in its novelty-and in its uniqueness. For a strictly mechanical view of things the killing resembles an eclipse. Unique as it is, it is supposed to have been essentially predictable. Perhaps if you had known the precise configuration and the accelerations of all the physical particles in the world at some appropriate moment, then this killing could have been calculated in advance. It is a mere case of a law-an eclipse, so to speak, of some sun-a point on some curve.

But for a statistical view the single killing of B by $A$ is an event against which an insurance provision could have been made in advance-not because any mortal could have predicted whether or no A would kill B, but because the death-rate of men of B's age and occupation can be statistically known with an approximate and probable accuracy, so as to make a policy insuring B's life a contract whose value is calculable, not on mechanical but upon statistical grounds.

Now you will easily recognize that the actual knowledge of vital phenomena which science possesses is, in the main, a statistical knowledge. It is the sort of knowledge which the mortality tables of the insurance companies exemplify. We know little of the history of individual organisms, and less of their mechanism, but we can and do study the statistics of groups of organisms. In such statistical terms heredity and variation are now constantly investigated. In such terms growth and disease, as well as death, economic prosperity and social transformations, financial and political processes, the geographical distribution of organisms and the gradual accumulation and change of the material as well as the mental products of civilization-in such statistical terms, I say, all such things come to be the objects of scientific description and explanation. To give an account of the special phenomena of life in terms of mechanism remains in practise a remote ideal, despite all the proofs that the vital processes, being subject to physical and chemical laws, must be, in some sense, if not wholly, then very largely mechanical in their nature. Life may be a case of 
mechanism; but its phenomena are best known to science in terms of statistical averages, of laws which hold approximately true regarding these averages, and of probabilities which are definable in such terms as are used when the insurance value of a life-policy is computed. The logic of the insurance actuary is essentially the same as the logic which is consciously or unconsciously used in dealing with all forms and grades of vital processes.

This general rule regarding the methods of the sciences of life is well known to you. For it is also known that, just as a mechanical theory of the details of the phenomena of life still remains a remote ideal, so too an historical knowledge of the individual events of the life of an organism is something which may possess upon occasion great moral or social or perhaps clinical interest, but can occupy but a part, and usually a very small part, of the interest of the sciences of life.

Into the study of human history itself, devoted as such a study naturally is to the sequences of individual events, natural science enters in so far as something of the nature of statistical knowledge is acquired. And therefore the use of deliberately statistical methods in historical study, the use which Dr. Woods has recently proposed-such a use, I say, is in principle nothing essentially opposed to methods long since inexactly and unconsciously employed. For the historiometry of Dr. Woods is in principle a legitimate extension and a logically legitimate refinement of the long since well-known disposition to explain human history in terms of "historical tendencies" and of "historical forces."

In fact, the term tendency is, in every exact usage which you can give it, an essentially statistical term. To say that $a$ has a tendency to lead to $b$ is to declare that a more or less certainly and definitely known proportion of events of the class $a$ are followed by events of the class $b$.

To introduce statistics into historical study is simply to try to make some such assertions about tendencies exact.

The constant extension of the use of statistical methods in all the sciences of life is something as familiar as it is momentous. Its very familiarity, in fact, tends to blind the minds of many to its real importance. In truth, the statistical view of nature has a logic of its own. Its three fundamental conceptions, that of an average, that of approximation and that of probability, are indeed not the only fundamental categories of our thought, but they are conceptions which go down to the very roots of our own intelligence as 
well as of our voluntary activity. It seems increasingly plausible to assert that these three conceptions, while they certainly have their special province, still, within that province go down to the roots of that nature of things which our sciences are studying. At all events, I find it hard to exaggerate the importance of those methods and of these ideas of natural science which are definable in terms of approximation and of probability, in the modern sense of those terms.

When Clerk Maxwell made his threefold classification of scientific methods, he did so with his eyes well open to the fact that by the statistical view of nature, and by statistical methods in science he meant something much wider and deeper than is the mere commonplace that statistical tables can be made by the census bureaus, and can be used by the insurance companies, or applied to the discovering of various special laws of nature. Let me remind you of what Maxwell had in mind.

\section{The Statistical View in Physics}

Clerk Maxwell was a physicist. His greatest treatise was that upon electricity and magnetism. The theory of electricity and magnetism follows methods which illustrate the mechanistic way of dealing with the problems of nature. Maxwell defined a system of differential equations in terms of which certain elementary electro-magnetic processes can be expressed. Assuming these equations to be true, one can compute the consequences of one's hypotheses, as Newton computed the consequences of supposing the law of the inverse squares to be true for a field of gravitative force. One can then compare the computed results with experience, and upon such computation and comparison with experiment one's method in this case depends. Such is an example of the essentially mechanical view of nature.

But Clerk Maxwell, working as he did at a time when the general theory of energy was in its period of most rapid development, was not content to confine himself to problems of the type of the theory of electricity. He also had his attention especially directed to those physical processes which are illustrated by the diffusion of gases, by the irreversible tendency of energy to pass over from available to unavailable forms, and by various analogous phenomena which can not be expressed in terms of the classic types of mechanical theories. 
Following the initiative of Clausius, but developing along lines of his own, Maxwell thereupon worked out his kinetic theory of gases. It is that theory of which he is thinking when he distinguishes the statistical way of viewing nature both from the historical and from the mechanical view.

In fact, when the kinetic theory of gases first defines its swarms of molecules, with their countless paths and collisions, it appears to be viewing a gas simply as a complex mechanism; and in certain respects this seeming is well founded. But the logic of the theory of probabilities, which the kinetic theory uses in deducing the physical properties of gases from the statistical averages of collisions, and free paths of the hypothetical molecules, is no longer reducible to the logic of mechanics. For the velocity, the path, and the collision of each individual molecule are all indifferent facts for this kinetic theory of gases; which devotes itself to the study of probabilities and of tendencies. And its methods are in part those which the procedure of the insurance actuaries exemplifies. The logic in question is one which in some respects still needs further elucidation. For even up to the present time the logic of the theory of probabilities is a controverted topic. But there are a few features of the situation about which nobody who looks carefully into the subject can retain, I think, any serious doubt.

First, then, the average behavior of a very large collection of irregularly moving objects has characters which are decidedly lawful, even although the laws in question are what may be called laws of chance.

The recent familiar use of statistical diagrams for illustrative purposes has made this law of chance more familiar to many classes of students than it was in the day when Maxwell wrote certain words which you will find in his "Theory of Heat." 1 These words give you the very heart of the statistical aspect of nature.

The distribution of the molecules according to their velocities is found to be of exactly the same mathematical form as the distribution of observations according to the magnitude of their errors, as described in the theory of errors of observation. ... Whenever in physical phenomena some cause exists over which we have no control, and which produces a scattering of the particles of matter, a deviation of observations from the truth, or a diffusion of velocity or of heat, mathematical expressions of this exponential form are sure to make their appearance.

1 Page 309 of the Appleton edition of 1875 . 
This, then, is in concrete form the law of random distribution, the form of iron necessity which one finds in the realm of chance.

All this law of chance variation was, of course, at that time no novelty, although the popular use of statistics has since made it more familiar. What was new, however, was the fact that when Maxwell computed the consequences which followed from supposing the existence of his swarm of colliding molecules with their chance distribution of velocities, he was able to deduce not only the principal physical properties of gases, but in particular those properties which, like all the phenomena which illustrate the sec-ond law of the theory of energy, are not expressible in terms of merely mechanical laws, unless these laws are applied to the case of a system complex enough to ensure that the velocities of its molecules shall approximate closely to this chance distribution.

Since Maxwell's time, the same theoretical methods have been applied to a vast range of physical phenomena, with the general result that the second law of the theory of energy is now generally regarded, by all except the extreme Energetiker, as essentially a statistical law. So viewed, the second law of energy becomes a principle stated wholly in terms of the theory of probability. It is the law that the physical world tends, in each of its parts, to pass from certain less probable to certain more probable configurations of its moving particles. As thus stated the second principle not only becomes a law of evolution, an historical principle, but also ceases to be viewed as any mechanically demonstrable or fundamentally necessary law of nature. Whether nature is a mechanism or not, energy, according to the kinetic theory, runs down hill as it does for statistical and not for mechanical reasons. Energy need not always run down hill; and in fact would not do so if there were present in nature any persistent tendency, however imperfect, towards a suitable sorting of molecules. Maxwell suggested in his image of the demons sorting the atoms of a gas, how such a tendency might make energy run up hill instead of down, without the violation of any mechanical principle.

More recently Boltzmann, in his further development of Maxwell's hypothesis, pointed out how the theory of probability itself requires that, in the course of very vast intervals of time, there must occur some occasional concentrations of energy and some sensible unmixings-some reversals of the diffusion of gases, in case indeed the kinetic theories are themselves true. And still more 
recently Arrhenius has suggested that the nebulae may furnish the conditions for the occasional if not the general reversal of the second law of the theory of energy. Of such speculations I can of course form no judgment. They interest us here only as examples of the logic of the statistical view of nature.

In sum, all these investigations have tended to this general result: If a law of the physical world does not appear consistent with the mechanical view of nature so long as you confine your attention to a single system of bodies, whose individual movements you follow and compute, this law may still become perfectly intelligible when viewed as the expression of the average behavior of a kinetic system complex enough to give an opportunity for the application of statistical laws, and for the use of the conception of probability.

\section{The Canonical Form of Scientific Theories}

All the foregoing instances may appear to you merely to suggest that, in dealing with mechanisms too complicated to be the object of a direct computation, our ignorance may force us to make use of statistical modes of computation. These statistical methods, you may say, are convenient devices whereby we neutralize, for certain special purposes, the defects of our mechanical knowledge.

If the insurance actuaries-so you may say-could use a sufficient knowledge of the world's mechanism, they would compute the precise time when each individual man is to die, just as the astronomers compute the eclipses. An almanac of mortality would take the place of the present nautical almanac. Everybody's funeral would be announced, if that were convenient, years in advance; and life insurance would appear to be a blundering and an awkward substitute for scientific prediction. Because and only because, as a fact, no knowledge of the differential equations of the precise movements of matter, and no exact measurements of the accelerations or of the other rates of change in these movements gives us the power to predict the phenomena of nature in their detail, including the movements which determine life and death, we are obliged to substitute a statistical definition of the probable tendencies of a definable proportion of great numbers of men to die, in a way which varies with their numbers and their ages, for the precise knowledge of the hour of each man's death which we 
should all regard as a scientific ideal, if we could know the mechanism of life and death. The statistical view is a mere substitute for a mechanical view which our ignorance makes us unable to use, in the individual case, with sufficient accuracy. Such may be your comment. The nautical almanac (so you may say) is the model of what applied science ought to be. The mortality table is the convenient summary due to a necessary scientific evil. It is a device for recording our ignorance of the details of the world's mechanism along with our imperfect knowledge of certain probable and approximate tendencies to which the averages of many human lives are subject.

In other words, you may be disposed to insist: "Mechanical theories are the canonical forms towards which a growing scientific knowledge guides our way. Computations of individual events in terms of invariant laws whose validity is independent of time, are the models of what our scientific ideals seek. The statistical view of very complex mechanisms is an asylum in which our ignorance, perforce, has to find its refuge whenever, as in the case of the swarms of molecules and the labyrinthine complications of organisms, the mechanical view of nature, as applied by us, loses its way."

In answer to this very natural comment, I am next led to say that, whether the natural world is a mechanism or not, the statistical view of nature would be, and so far as we know the facts is, applicable to sufficiently complicated systems of things and events, not as a mere substitute for these more exact computations which our ignorance of mechanical laws makes necessary, but as an expression of a very positive, although only probable and approximate, knowledge, whose type all of the organic and social sciences, as well as most aspects of the inorganic sciences, illustrate. There is therefore good reason to say that not the mechanical but the statistical form is the canonical form of scientific theory, and that if we knew the natural world millions of times more widely and minutely than we do, the mortality tables and the computations based upon a knowledge of averages would express our scientific knowledge about individual events much better than the nautical almanac would do. For our mechanical theories are in their essence too exact for precise verification. They are verifiable only approximately. Hence, since they demand precise verification, we never know them to be literally true. 
But statistical theories, just because they are deliberate approximations, are often as verifiable as their own logical structure permits. They often can be known to be literally, although only approximately, true.

This assertion is, in its very nature, a logical assertion. It is not any result of any special science, or of any one group of sciences. It solves no one problem about vitalism. It is a general comment on the value of the statistical point of view.

But, if the assertion is true, it tends to relieve us of a certain unnecessary reverence for the mechanical form of scientific theory -a reverence whose motives are neither rationally nor empirically well founded. It is the merit of Charles Peirce to have emphasized these logical considerations. Their importance for the study of scientific methods has grown greater with every year since 1891 , when he began the publication of his remarkable papers in the Monist, entitled: "The Architecture of Theories," "The Doctrine of Necessity Examined" and "The Law of Mind." These papers are fragmentary; and yet in their way they are classical statements of the limitations of the mechanical view of nature, and of the significance of the statistical view of nature.

As I close, let me merely outline some aspects of Peirce's extension of the statistical view of nature beyond the range which Maxwell's and Boltzmann's study of the theory of gases directly exemplified.

\section{Application of the Statistical View to Theories of Non-Mechanical Systems. Aggregation and Assimilation as Statistical Tendencies}

It at first seems, I have said, as if the statistical methods of the kinetic theory were applicable only to mechanisms whose complications were too vast to make it possible to follow in individual detail their necessary sequences of movements.

But this seeming is unfounded. Let me summarize in my own words a few considerations which Peirce summarily states, and which, to my mind, get a constantly increasing importance as the statistical view of nature comes to be applied to wider and wider fields of research.

Suppose an aggregate of natural objects which contains a very great number of members, each one of which is subject to some 
more or less exhaustively definable range of possible variations. These objects may be things or events, at your pleasure. They may be molecules or stars or cells or multicellular organisms or members of a society or observations of a physical quantity or proposals of marriage or homicides or literary compositions or moral agents or whatever else you will. The essential basis which is needed for a statistical view of such an aggregate is this:

First, the members of each aggregate must actually form a collection which is, for some physical or moral reason, a genuine and therefore in some way a definable whole.

Next, some more or less systematic tendency towards a mutual assimilation of the fortunes, the characters or the mutual relations of the members of this aggregate must exist. This tendency toward mutual assimilation may be of very various sorts.

The policyholders of an insurance company tend to assimilate the fortunes of their various investments when they all of them pay their premiums to the same company. The stars tend to a certain assimilation of the mutual relations amongst those photographs of their various spectra which chance to get collected on the photographic plates of the same astronomical observatory. For, as a consequence of this aggregation of photographs, the stellar spectra in question may tend to be classified; and the logical, as well as the other socially important, and the physical fortunes of objects which are once viewed or arranged or tabulated as objects belonging to the same class, tend, in general, to a further mutual assimilation.

Birds of a feather not only flock together, but tend to get statistically similar fortunes, when they come into chance contact with other birds or with breeders, with hunters or with biometrical statisticians.

All objectively well-founded classification is not only founded upon real similarities amongst the objects which belong to an aggregate, but tend to some increase of these similarities, in so far as these objects are not changeless mathematical entities, but are natural objects, whose fortunes are subject to change.

One of the most widely applicable laws of nature is, in fact, the law, wholly indefinable in mechanical terms, but always expressible in terms of statistical tendencies-the law that aggregation tends to result in some further and increasing mutual assimilation of the members of the aggregate. This assimilation may express itself in 
the fact that one classification or aggregation leads both logically and physically to another and deeper and also wider aggregation.

If the stars are already physically classified into two distinct drifts, which move through each other in two different directions, and if the stars in question tend to get the photographs of their spectra assembled in the same observatory, then the classes into which the photographs tend in the long run to be grouped also tend to be such that, at least for some one resulting classification or aggregation of the photographs, the photographs of the spectra of the stars of one of the star drifts are grouped together, not only in the ideas which the astronomers form, but in the physical arrangements towards which certain groups of photographs, of symbols and of statistical tables, persistently tend.

The principles here involved depend upon the sorts of assimilation which the radiant phenomena of light make possible. For a photograph is a physical expression of a certain tendency whereby the structure of a photographic plate tends to be assimilated to the molecular structure and state of a radiating object--say a star. When the photographs of stellar spectra are grouped in classes, a secondary assimilation tends to take place, since similar spectra tend to get either placed or tabulated in similar ways. When this secondary assimilation of the photographs leads to an indirect discovery of the existence of the two star drifts themselves, a tertiary assimilation of the fortunes of those stars whose proper motions are sufficiently similar takes place, and tends to get represented in the knowledge of different astronomers.

The ideas of these various astronomers tend to further assimilation through the means used in scientific communication. The radiation of scientific knowledge continues the natural process which the radiation of light and the making of photographs of stellar spectra have already illustrated, and the rule continues to be illustrated that mutual assimilation is one aspect of classification and aggregation, and is a cumulative statistical tendency which accompanies them both.

The insurance companies and the transformation of modern civilization through the extension and aggregation of modes and devices whereby insurance is accomplished, furnish numerous other examples of this law of the fecundity of aggregation. The law, as I have said, holds in general for non-mechanical systems, although, as stellar evolution seems to indicate, it can also hold 
for mechanical systems. It may hold, in fact, for all natural processes which involve evolution.

Clerk Maxwell himself believed that the sharp distinction which separate the different classes of elementary atoms, and the different types of molecular structure which determine the spectra of the molecules of different elements, are signs that no kinetic theory of the evolution of the chemical elements would ever be possible. It is precisely here that the latest advances, on the still so imperfectly defined outlying boundaries of physical and of chemical research, give a new significance to the statistical view of nature, by showing that if we take account of sufficiently large aggregates of things and of events, a kinetic theory of the evolution of chemical elements becomes a possibility worthy of future investigation, and certain to receive, in connection with the phenomena of radioactivity, further investigation upon statistical lines, whatever be the further fortunes of the mechanical view of nature, or of this problem about the evolution of the elements.

Of such speculations one can say that, if ever a theory of the evolution of the chemical elements becomes feasible, it will be, in part at least, a statistical theory, and will illustrate in new ways how widespread in material nature is the tendency to that mutual assimilation which all the phenomena of radiant energy illustrate, and of which the relatively uniform constitution and distribution of each one of the various chemical elements through vast ranges of the physical universe may well be the result.

In brief, the evolution of stars, of elements, of social orders, of minds and of moral processes, apparently illustrates the statistical fecundity of nature's principal tendency-the tendency to that mutual assimilation which both defines aggregates, that is, real classes of natural objects, and tends to keep these classes or aggregates permanent in the world and to increase both their wealth of constitution and their extent.

Now it is this principle of the fecundity of aggregation which seems to be the natural expression, in statistical terms, for the tendency of nature towards what seems to be a sort of unconscious teleology-towards a purposiveness whose precise outcome no finite being seems precisely to intend. It is a statistically definable rule that changeable aggregates, when they are real at all, result from likenesses which their very existence tends both to increase and to diversify. The social fecundity of the principle of insurance 
illustrates this natural tendency. That marvelous result of the aggregation of scientific observers, of tabulations and of photographs, of the radiant phenomena which makes the stars visible and of the microscopic phenomena and the logical interests which make probability definable-that marvelous result of these various aggregations which constitutes the whole procedure and outcome of modern inductive science itself, is an expression of this same general tendency-apparently the most vital and the most vitalizing tendency both of the physical and of the spiritual world-the tendency of aggregation and of classification to be fruitful both of new aggregations and of the orderly array of natural classes and of natural laws.

In the purely logical and mathematical worlds this tendency can get, and does get, precise description in terms of the pure logic of number and of order. In the physical world, in the world of time and change, this principle gets further expressed as a statistical rather than a mechanical law-the law that classes, aggregations and organizations tend towards a definable sort of evolution.

As Charles Peirce pointed out, you need not suppose the real world to be mechanical in order to define and to conceive this sort of evolution. You need only suppose (I) the presence of the justmentioned tendency to form aggregates, and of the mutual assimilation of the various parts of nature; (2) the statistically definable tendency to some sort of sorting or selection of the probable results to which any definable average constitution of the natural world at any moment leads; and (3) a tendency-and once more, a statistical and non-mechanical tendency, towards a formation of habits, and towards a repetition of such types of movement as have once appeared. Suppose these three tendencies (aggregation, selection and habit-and the statistical method shows these three to be widespread in the physical world); suppose these three, and you can define a process of evolution, never mechanical and never merely expressive of any previously settled designs, either of gods or of men. This process of evolution will then lead from mere chance towards the similation of mechanism, from disorderly to a more orderly arrangement, not only of things and of individual events, but of the statistically definable laws of nature; that is, of the habits which nature gathers as she matures. The philosophy of nature which will result will show how nature may well tend to appear in certain aspects more and more teleological, and to mani- 
fest what Greek vitalism found in nature. Whether the whole world is ultimately and consciously teleological or not, this view of nature would of course be unable to decide. But it would lay stress upon the thought that what is indeed most vital about the world is that which also characterizes the highest life of the spirit, namely, the fecundity of whatever unites either electrons or souls or stars into streams or into other aggregations that, amid all chances, illustrate some tendency to orderly cooperation.

If this view of nature has any foundation, gentlemen, then, as the whole progress of inductive science illustrates, the way to further such scientific evolution is to get together, and to leave the rest to the statistically definable tendencies of nature. These are tendencies away from the chance distributions which the bellshaped curve of random distribution illustrates, towards the orderliness of which the mechanical view of nature gives us one illustration, and by no means the most probably true illustration.

I should suppose, then, that whatever notes you may compare in these meetings, you will probably frequently and variously illustrate the statistical view of nature. This view is ill understood by those who think only how dry statistical tables and averages may seem. Mechanism is rigid, but probably never exactly realized in nature. But life, although it has its history, has also its statistics. And averages cease to be dry when they are averages that express the unities and the mutual assimilations in which the common ideals and interests, the common hopes and destinies of the men, of the social orders, of the deeds-yes, and perhaps of the stars and of all the spiritual world are bound up and are expressed.

Do you wish to experiment upon some new processes of social aggregation, of mutual assimilation, and of the study of photographs of your various spiritual spectra?

This practical question is for you to consider. 
